\title{
Antihypertensive and Renoprotective Effects of Dietary Flaxseed and its Mechanism of Action in Deoxycorticosterone Acetate-Salt Hypertensive Rats
}

\author{
Yusuke Watanabe Kaori Ohata Ayaka Fukanoki Naoto Fujimoto \\ Maruri Matsumoto Naseratun Nessa Hiroe Toba Miyuki Kobara Tetsuo Nakata \\ Division of Pathological Sciences, Department of Clinical Pharmacology, Kyoto Pharmaceutical University, Kyoto, Japan
}

\section{Keywords}

Flaxseed · Alpha-linolenic acid · Hypertension · Sympathetic nervous system Brain inflammation

\begin{abstract}
Background/Aims: Flaxseed contains alpha-linolenic acid (ALA), lignans, and dietary fiber, and its intake lowers blood pressure in hypertensive patients. Here, we examined the effects of flaxseed powder, which includes all flaxseed components, flaxseed oil, composed mainly of ALA, flaxseed lignan, and flaxseed fiber, on hypertension and renal damage induced by deoxycorticosterone acetate (DOCA)-salt. Then, we investigated the mechanisms of action associated with the effects of flaxseed. Methods: Flaxseed powder, oil, lignan, or fiber was administered to DOCA-salt rats. Systolic blood pressure (SBP), urinary protein excretion, renal angiotensin converting enzyme (ACE) activity, sympathetic nerve activity, and gene expression of inflammatory mediators in the kidney and hypothalamus were measured. Results: Flaxseed powder and oil reduced the increases in SBP and urinary protein excretion induced by DOCA-salt treatment, whereas lignan and fiber had no effects. Flaxseed oil suppressed the increase in renal ACE activity, sympathetic nerve activity, and gene expression of renal and hypothalamic inflammatory mediators. Conclusion: Flaxseed has antihypertensive and renoprotective effects in DOCA-salt rats. These
\end{abstract}

effects are likely principally exerted by ALA. Furthermore, the suppression of renal ACE activity, sympathetic nerve activity, and inflammation is partly involved in the effects of flaxseed.

(c) 2019 S. Karger AG, Basel

\section{Introduction}

Dietary intervention has long been considered as good strategy for controlling blood pressure [1, 2]. Flaxseed was reported to decrease the increased blood pressure and renal damage in hypertensive model rats and hypertensive patients [3-5]. Therefore, dietary intake of flaxseed is considered to be a useful strategy for managing blood pressure.

Alpha-linolenic acid (ALA), lignans, and dietary fiber are abundant in flaxseed [6]. Among these components, ALA and lignans exert antihypertensive effects by inhibiting the circulating renin-angiotensin system (RAS) [7, 8]. Furthermore, dietary fiber was also reported to exhibit antihypertensive effects, although the detailed mechanisms have not been clarified [9]. However, the involvement of these individual constituents in the antihypertensive effects of flaxseed has not been elucidated and the involvement of mechanisms of action other than circulating RAS inhibitory action remains unclear. 
The deoxycorticosterone acetate (DOCA)-salt hypertensive rat is one of the most common experimental models for investigating antihypertensive action. Malignant hypertension induced by DOCA-salt treatment leads to renal damage accompanied by an activation of RAS and inflammation in the kidney [10-12]. DOCA-salt treatment also triggers overactive sympathetic nervous system tone and inflammation in autonomic nerve centers [1315]. An increased sympathetic nervous system leads to the development and maintenance of hypertension [16]. Recently, inflammation in the brain was reported to be one of the causes of sympathoexcitation in hypertension [17]. Brain inflammation followed by an overactive sympathetic nervous system may be a key element in the pathogenesis of hypertension. In addition, this model is not expected to have antihypertensive effects from the inhibition of circulating RAS [18]. Therefore, a model of DOCA-salt-induced hypertension is useful for examining circulating RAS-independent mechanisms of hypertension.

In the present study, we examined the preventive effects of flaxseed powder, which includes ALA, lignans, and dietary fiber, and flaxseed oil, composed mainly of ALA, on the increase in blood pressure and induction of renal damage in DOCA-salt rats. We also assessed the effects of flaxseed lignan and flaxseed fiber in DOCA-salt rats to elucidate the involvement of these components in the antihypertensive effects. Last, the mechanisms of action associated with the antihypertensive and renoprotective effects of flaxseed oil were investigated, focusing on renal angiotensin-converting enzyme (ACE) activity, sympathetic nerve activity, and kidney and brain inflammation.

\section{Materials and Methods}

\section{Reagents and Animals}

DOCA was purchased from Nacalai Tesque (Kyoto, Japan). Flaxseed powder, flaxseed oil, flaxseed lignan, and flaxseed fiber were kindly provided by Nippon Flour Mills Co., Ltd. (Tokyo, Japan). Male Wistar/ST rats (150-180 g, Japan SLC, Shizuoka, Japan) were housed in an environmentally controlled room with a 12-h light/dark cycle and given standard rodent chow and tap water ad libitum. All rats were handled in accordance with the Institutional Animal Care and Use Committee of Kyoto Pharmaceutical University following the guidelines of the National Research Council and National Institute of Health.

\section{Experimental Procedure}

Right unilateral nephrectomy was performed on rats under anesthesia with a mixture of medetomidine, midazolam, and butorphanol. After surgery, rats ( $n=6 /$ group) received weekly sub- cutaneous injections of DOCA at $40 \mathrm{mg} / \mathrm{kg}$ body weight on days 0,7 , and 14 and were provided $0.5 \% \mathrm{NaCl}$ in drinking water from day 0 to 21 to induce hypertension. Rats subjected to sham operation $(n=4)$ were used as a sham group. The volume of water intake and urine output for $24 \mathrm{~h}$ were measured. Urine samples were collected, and urinary protein excretion for $24 \mathrm{~h}$ was measured using a commercially available kit (Micro TP-Test Wako; Wako, Osaka, Japan). Systolic blood pressure (SBP) was measured by the tail-cuff method (Model UR-5000; Ueda, Nagano, Japan). At the end of the experiment, the kidney and hypothalamus were removed and stored at $-80^{\circ} \mathrm{C}$. Flaxseed powder was mixed with chow for a daily intake of $1.2 \mathrm{~g}$ (low powder group) or $2.4 \mathrm{~g}$ (high powder group) and administered to rats. Flaxseed oil was administered once daily at doses of $0.6 \mathrm{~mL} /$ day (low oil) or $1.2 \mathrm{~mL} /$ day (high oil) by gavage. The doses for the powder group and oil group were set such that the amount of ALA was equal. Flaxseed lignan and flaxseed fiber were mixed with chow for a daily intake of $6.6 \mathrm{mg}$ or $0.26 \mathrm{~g}$, respectively, and administered to rats. The doses for the lignan group and fiber group were set based on $1.2 \mathrm{~g}$ of flaxseed powder (low powder) containing $6.6 \mathrm{mg}$ of lignan and $0.26 \mathrm{~g}$ of fiber. DOCA-salt hypertensive rats given the vehicle were used as a control group.

\section{Measurement of Sympathetic Nerve Activity}

Measurement of blood pressure and sympathetic nerve activity in conscious rats was performed as described previously $[19,20]$. On day 21, the left femoral artery was cannulated with polyethylene tubing, and the free end of the catheter was connected to a pressure transducer (MP5100; Edwards Lifescience, Tokyo, Japan). The SBP and mean arterial pressure (MAP) were recorded using Fluclet ${ }^{\circledR}$ Jr.2 (NAGAOKA \& Co., Ltd., Hyogo, Japan) under freely moving, awake conditions. Rats were next placed on a reciprocal shaker (150 rpm, TAITEC, Saitama, Japan), and the same experiment as above was conducted under shaker stress conditions. The SBP was analyzed by power spectral analysis using the wavelet method of Fluclet ${ }^{\circledR}$ Jr.2, and a power spectral density of low-frequency band (LF: $0.25-0.75 \mathrm{~Hz}$ ) of SBP fluctuation was calculated. The power spectral density of LF-SBP $(\mathrm{mm} \mathrm{Hg} / \sqrt{ } \mathrm{Hz})$ was used as an index of sympathetic nerve activity.

\section{Measurement of ACE Activity}

ACE activity in the kidney was measured using a synthetic substrate, hippuryl-His-Leu, specifically designed for ACE (Peptide Institute, Osaka Japan) [11]. The kidney homogenate was centrifuged, and the supernatant was incubated for $10 \mathrm{~min}$ at $37^{\circ} \mathrm{C}$ with $5 \mathrm{mmol} / \mathrm{L}$ hippuryl-His-Leu. The reaction was terminated by the addition of $3 \%$ metaphosphoric acid, and the mixture was centrifuged. The supernatant was applied to a reversed-phase column (4.6 mm i.d. $\times 250 \mathrm{~mm}$; Tosoh Corporation, Kanagawa, Japan) and eluted with $10 \mathrm{mmol} / \mathrm{L} \mathrm{KH}_{2} \mathrm{PO}_{4}$ and $\mathrm{CH}_{3} \mathrm{OH}$ (1:1, pH 3.0). Hippuric acid was detected by ultraviolet absorbance at $218 \mathrm{~nm}$. One unit of ACE activity was defined as the amount of enzyme that cleaved $1 \mathrm{mmol}$ of hippuric acid per min.

\section{RNA Isolation and Quantitative Real-Time PCR}

Total RNA was isolated from rat kidney and hypothalamus using Isogen reagent (Nippon Gene, Tokyo, Japan), and cDNA was synthesized from total RNA $(0.5 \mu \mathrm{g})$ using PrimeScript RT reagent Kit (Takara Bio Inc., Shiga, Japan) as described previously [21, 22]. Real-time PCR was performed with SYBR Premix Ex Taq II 
Table 1. List of primers used for real-time PCR

\begin{tabular}{lll}
\hline Gene & Forward $\left(5^{\prime}-3^{\prime}\right)$ & Reverse $\left(5^{\prime}-3^{\prime}\right)$ \\
\hline GAPDH & GGCACAGTCAAGGCTGAGAATG & ATGGTGGTGAAGACGCCAGTA \\
IL- $1 \beta$ & CAGCTTTCGACAGTGAGGAGA & GTCGAGATGCTGCTGTGAGA \\
IL-6 & TCTCCTCTCCGGACTTGTGAA & CTCTCCGCAAGAGACTTCCA \\
TNF- $\alpha$ & TAGCAAACCACCAAGCGGAG & TGAAATGGCAAACCGGCTGA \\
MCP- 1 & TGTTCACAGTTGCTGCCTGT & GATCTCACTTGGTTCTGGTC \\
\hline
\end{tabular}

PCR, polymerase chain reaction; GAPDH, glyceraldehyde-3-phosphate dehydrogenase; IL-1 $\beta$, interleukin-1 beta; IL-6, interleukin-6; TNF- $\alpha$, tumor necrosis factor-alpha; MCP-1, monocyte chemoattractant protein-1.

(Takara Bio Inc.) using the Thermal Cycler Dice Real-Time System (TP850, Takara Bio Inc.). The primer sequences used for real-time PCR are listed in Table 1. Data were normalized to GAPDH expression by the $\Delta \Delta \mathrm{C}_{\mathrm{T}}$ comparative method and expressed as a fold change compared with the sham group.

\section{Statistical Analysis}

All data were expressed as means \pm SEM. Results were analyzed by one-way analysis of variance for repeated-measures, followed by Fisher's protected least significant difference test or one-way analysis of variance for multiple comparisons followed by the protected least significant difference test. A value of $p<0.05$ was considered significant.

\section{Results}

\section{Effects of Flaxseed Powder and Flaxseed Oil on}

Hypertension and Renal Damage in DOCA-Salt Rats

In the control group, the SBP was increased to $>200 \mathrm{~mm} \mathrm{Hg}$ and urinary protein excretion was increased to $>300 \mathrm{mg} /$ day on day 21 . Low-dose and highdose flaxseed powder both suppressed the development of hypertension from the early phase (day 7) of DOCAsalt treatment and significantly inhibited the increase in SBP as compared with the control group throughout the experimental period (Fig. 1a). Similarly, these groups had a significant decrease in urinary protein excretion as compared with the control group (Fig. 1b). Low-dose and high-dose flaxseed oil also suppressed the development of hypertension from the early phase (day 7) of DOCA-salt treatment and significantly inhibited the increase in SBP as compared with the control group throughout the experimental period (Fig. 1c). High-dose flaxseed oil significantly decreased urinary protein excretion as compared with the control group (Fig. 1d). There was no significant difference in water intake or urine output among the groups, thus salt loading was equivalent (Table 2).

\section{Effects of Flaxseed Lignan and Flaxseed Fiber on} Hypertension and Renal Damage in DOCA-Salt Rats

Weekly increases in SBP and urinary protein excretion were observed in the control group. Lignan and fiber had no effects on these parameters (Fig. 2a, b) in contrast to flaxseed powder and flaxseed oil. There was no significant difference in water intake or urine output among the groups (Table 3).

\section{Effects of Flaxseed Oil on Renal ACE Activity in DOCA-Salt Rats}

The effects of flaxseed oil on ACE activity in the kidney were examined. As shown in Figure 3, ACE activities in the control group were higher than that in the sham group. Flaxseed oil treatment significantly suppressed the activation of ACE observed in the DOCA-salt hypertensive rat kidney.

\section{Effects of Flaxseed Oil on MAP and Sympathetic}

Nerve Activity in DOCA-Salt Rats

The effects of flaxseed oil on MAP and sympathetic nerve activity were first examined under free-moving, awake conditions. As shown in Figure $4 \mathrm{a}$ and b, flaxseed oil significantly suppressed the increases in MAP and sympathetic nerve activity in DOCA-salt rats. Next, the effects of flaxseed oil on MAP and sympathetic nerve activity were examined under shaker stress conditions. As shown in Figure $4 \mathrm{c}$ and d, the increases in MAP and sympathetic nerve activity induced by shaker stress in the DOCA-salt rats were reduced by flaxseed oil.

\section{Effects of Flaxseed Oil on the Gene Expression of Inflammatory Cytokines and Chemokines in DOCA-Salt Rat Kidney and Brain}

The effects of flaxseed oil on the gene expression of interleukin-1 beta (IL-1 $\beta$ ), IL-6, tumor necrosis factoralpha (TNF- $\alpha$ ), and monocyte chemoattractant protein-1
Watanabe/Ohata/Fukanoki/Fujimoto/ Matsumoto/Nessa/Toba/Kobara/Nakata 
Table 2. The changes in water intake and urine volume in the control, low-powder, high-powder, low-oil, and high-oil group

\begin{tabular}{|c|c|c|c|c|c|}
\hline \multirow[t]{2}{*}{ Parameters } & \multirow{2}{*}{$\begin{array}{l}\text { Experimental } \\
\text { group }\end{array}$} & \multicolumn{4}{|l|}{ Day } \\
\hline & & 0 & 7 & 14 & 21 \\
\hline \multirow{5}{*}{$\begin{array}{l}\text { Water intake, } \\
\mathrm{mL} / \text { day }\end{array}$} & Control & $30.1 \pm 1.5$ & $76.0 \pm 10.0$ & $93.4 \pm 15.8$ & $80.8 \pm 26.4$ \\
\hline & Low powder & $34.1 \pm 0.9$ & $52.2 \pm 5.5$ & $79.6 \pm 7.9$ & $75.4 \pm 10.6$ \\
\hline & High powder & $31.0 \pm 2.4$ & $64.8 \pm 8.7$ & $106.6 \pm 11.3$ & $96.0 \pm 15.8$ \\
\hline & Low oil & $30.6 \pm 0.7$ & $88.4 \pm 13.7$ & $109.2 \pm 15.7$ & $88.6 \pm 10.9$ \\
\hline & High oil & $29.7 \pm 1.5$ & $92.8 \pm 16.7$ & $101.0 \pm 20.1$ & $95.0 \pm 15.1$ \\
\hline \multirow{5}{*}{$\begin{array}{l}\text { Urine volume, } \\
\mathrm{mL} / \text { day }\end{array}$} & Control & $16.5 \pm 1.4$ & $61.2 \pm 8.1$ & $74.6 \pm 13.8$ & $63.4 \pm 21.1$ \\
\hline & Low powder & $19.8 \pm 1.8$ & $35.8 \pm 3.7$ & $57.4 \pm 8.3$ & $54.2 \pm 6.3$ \\
\hline & High powder & $18.2 \pm 0.8$ & $48.6 \pm 6.1$ & $74.0 \pm 11.5$ & $79.2 \pm 12.7$ \\
\hline & Low oil & $19.8 \pm 1.3$ & $67.6 \pm 13.4$ & $87.0 \pm 11.8$ & $66.8 \pm 9.5$ \\
\hline & High oil & $21.6 \pm 1.2$ & $73.2 \pm 14.7$ & $73.2 \pm 14.4$ & $74.8 \pm 14.5$ \\
\hline
\end{tabular}

The values represent the mean \pm SEM of data from 6 animals.
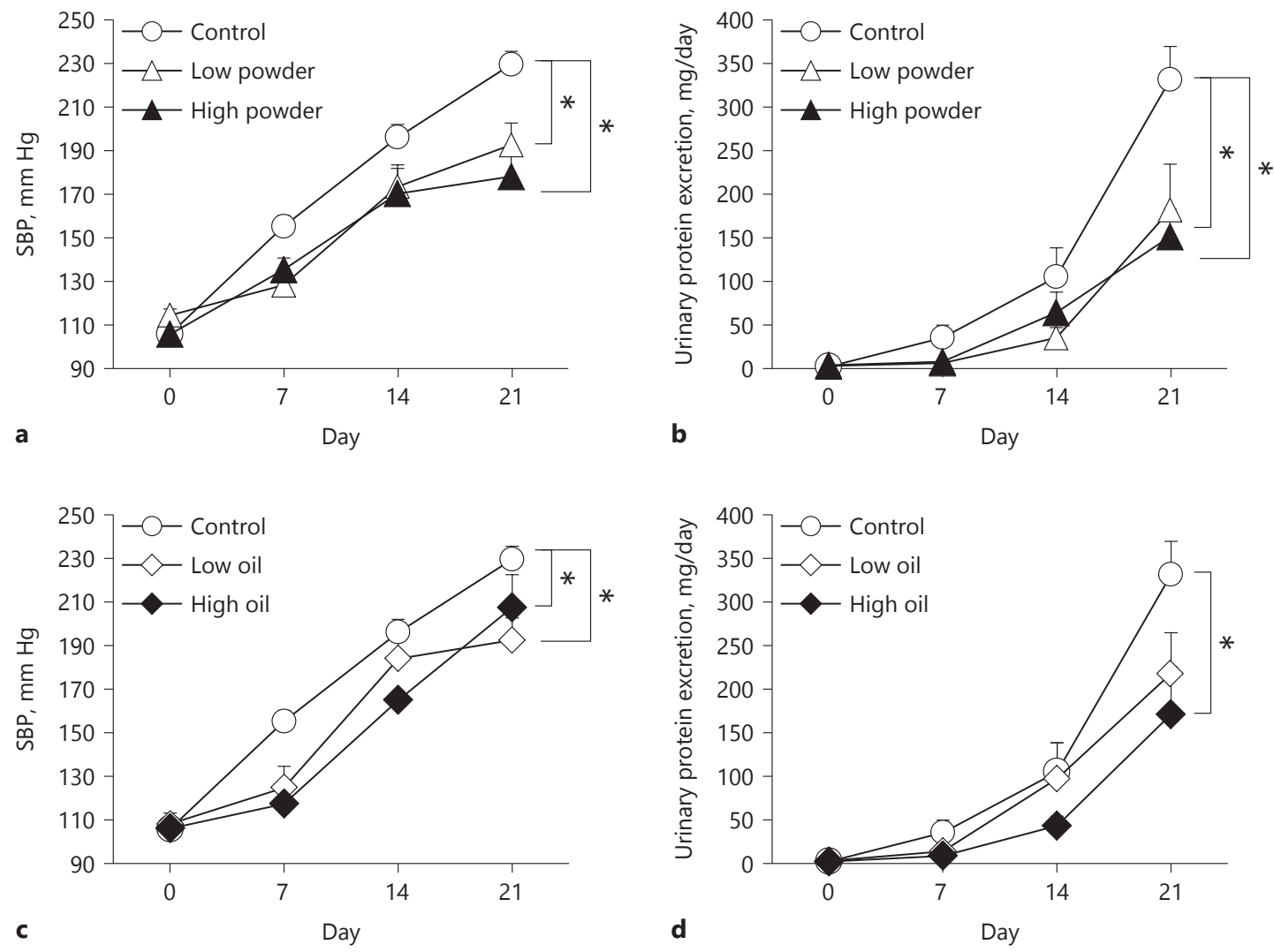

Fig. 1. Effects of flaxseed powder and flaxseed oil on the SBP and urinary protein excretion in DOCA-salt rats. a, b Flaxseed powder (low, $1.2 \mathrm{~g} /$ day; high, $2.4 \mathrm{~g} /$ day) supplemented diets were administered from day 0 to day 21. c, d Flaxseed oil (low, $0.6 \mathrm{~mL} /$ day; high, $1.2 \mathrm{~mL} /$ day) was administered once daily from day 0 to day

21 by gavage. The $\operatorname{SBP}(\mathbf{a}, \mathbf{c})$ and urinary protein excretion $(\mathbf{b}, \mathbf{d})$ were measured at the indicated time points. Data points and bars show the mean \pm SEM of data from 6 animals. ${ }^{*} p<0.05$ versus the control group. SBP, systolic blood pressure. 


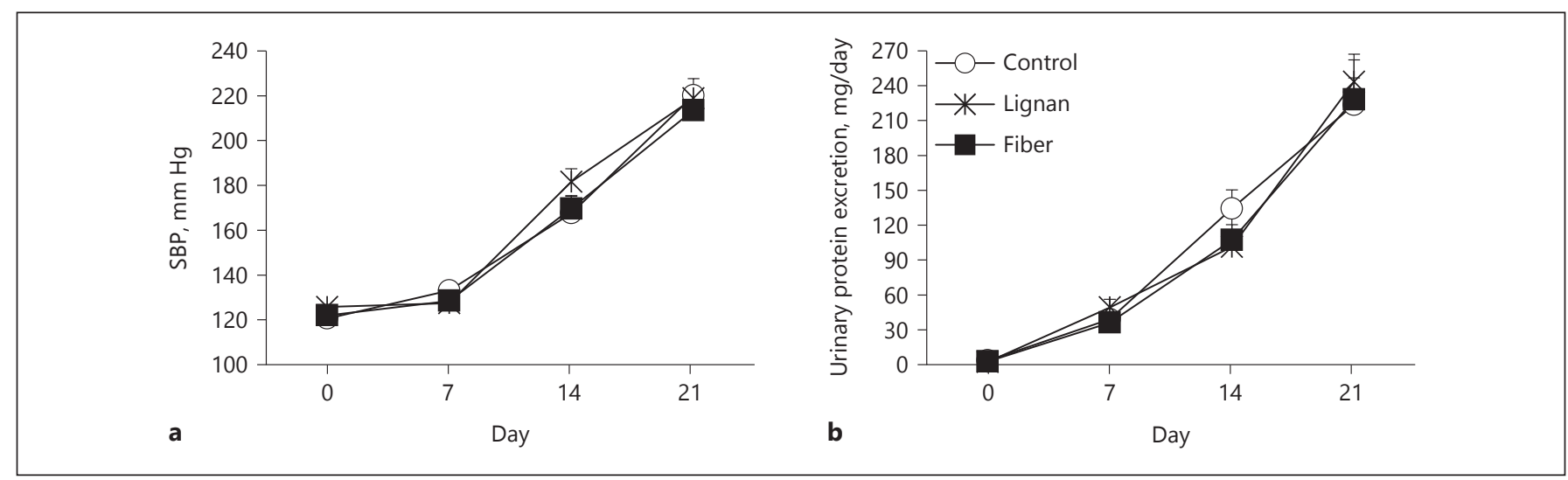

Fig. 2. Effects of flaxseed lignan and flaxseed fiber on the SBP and urinary protein excretion in DOCA-salt rats. a, b Flaxseed lignan (6.6 $\mathrm{mg} /$ day) supplemented diet and flaxseed fiber $(0.26 \mathrm{~g} /$ day $)$ supplemented diet were administered from day 0 to day 21 . The SBP (a) and urinary protein excretion (b) were measured at the

indicated time points. Data points and bars show the mean \pm SEM of data from 6 animals. There was no significant difference between the control group and the lignan or fiber group. SBP, systolic blood pressure.

Table 3. The changes in water intake and urine volume in the control, lignan, and fiber group

\begin{tabular}{|c|c|c|c|c|c|}
\hline \multirow[t]{2}{*}{ Parameters } & \multirow{2}{*}{$\begin{array}{l}\text { Experimental } \\
\text { group }\end{array}$} & \multicolumn{4}{|l|}{ Day } \\
\hline & & 0 & 7 & 14 & 21 \\
\hline \multirow{3}{*}{$\begin{array}{l}\text { Water intake, } \\
\mathrm{mL} / \text { day }\end{array}$} & Control & $35.4 \pm 2.2$ & $91.6 \pm 10.2$ & $93.0 \pm 9.2$ & $66.0 \pm 14.5$ \\
\hline & Lignan & $36.1 \pm 1.4$ & $83.7 \pm 3.5$ & $93.9 \pm 8.8$ & $67.2 \pm 6.1$ \\
\hline & Fiber & $34.5 \pm 2.2$ & $69.3 \pm 3.6$ & $92.0 \pm 9.9$ & $66.4 \pm 9.5$ \\
\hline \multirow{3}{*}{$\begin{array}{l}\text { Urine volume, } \\
\mathrm{mL} / \text { day }\end{array}$} & Control & $18.8 \pm 1.7$ & $76.8 \pm 13.0$ & $71.2 \pm 9.8$ & $76.8 \pm 11.3$ \\
\hline & Lignan & $19.0 \pm 1.3$ & $63.5 \pm 3.2$ & $74.4 \pm 6.2$ & $72.6 \pm 7.9$ \\
\hline & Fiber & $17.8 \pm 2.4$ & $49.9 \pm 3.7$ & $73.4 \pm 8.4$ & $78.8 \pm 8.6$ \\
\hline
\end{tabular}

The values represent the mean \pm SEM of data from 6 animals.

(MCP-1) in the kidney and the hypothalamus were examined. As shown in Figure 5, the control group had higher expression of IL- $1 \beta$, IL- 6 , TNF- $\alpha$, and MCP- 1 mRNA than the sham group in both regions. Flaxseed oil prevented the increased expression of these genes in the control group.

\section{Discussion}

In the present study, we confirmed that dietary flaxseed suppressed the development of hypertension in DOCA-salt rats. Flaxseed powder was reported to have antihypertensive effects at a dose of $30 \mathrm{~g} /$ day in a clinical trial [3]. The doses of flaxseed powder in this study are approximately 2-4 times that in the above clinical study when converted to a human dosage. On the other hand, flaxseed powder-supplemented diets at a concentration of $10 \%(\mathrm{w} / \mathrm{w})$ reduced the blood pressure in a hypertensive rat model [4]. The concentration of flaxseed powder in the chow was $5 \%(\mathrm{w} / \mathrm{w})$ in the low-powder group and $10 \%(\mathrm{w} / \mathrm{w})$ in the high-powder group in this study; the daily intake of chow in the present study was approximately $24 \mathrm{~g}$. Therefore, the doses of flaxseed powder used in this study were reasonable for evaluating its effects on hypertension and renal damage in the rat model.

Flaxseed powder is rich in ALA, lignans, and dietary fiber, which are involved in antihypertensive action [5]. In the present study, the effects of flaxseed powder on hypertension and renal damage were almost the same as those of flaxseed oil, which is mainly composed of ALA. Moreover, flaxseed lignan and fiber had no significant ef- 
Fig. 3. Effects of flaxseed oil on renal ACE activity in DOCA-salt rats on day 21. Flaxseed oil $(1.2 \mathrm{~mL} /$ day $)$ was administered once daily from day 0 to 21 by gavage. Rats were sacrificed on day 21, the kidney was removed, and the ACE activity in the kidney was measured. Columns and bars show the mean \pm SEM of data from 4 or 6 animals. ${ }^{*} p<0.05$ versus the control group. $\mathrm{ACE}$, angiotensin-converting enzyme.

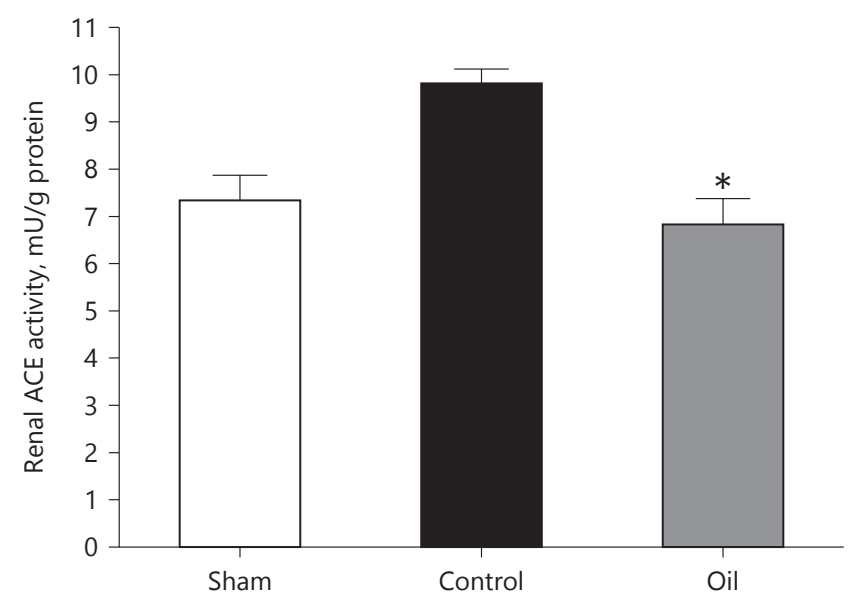

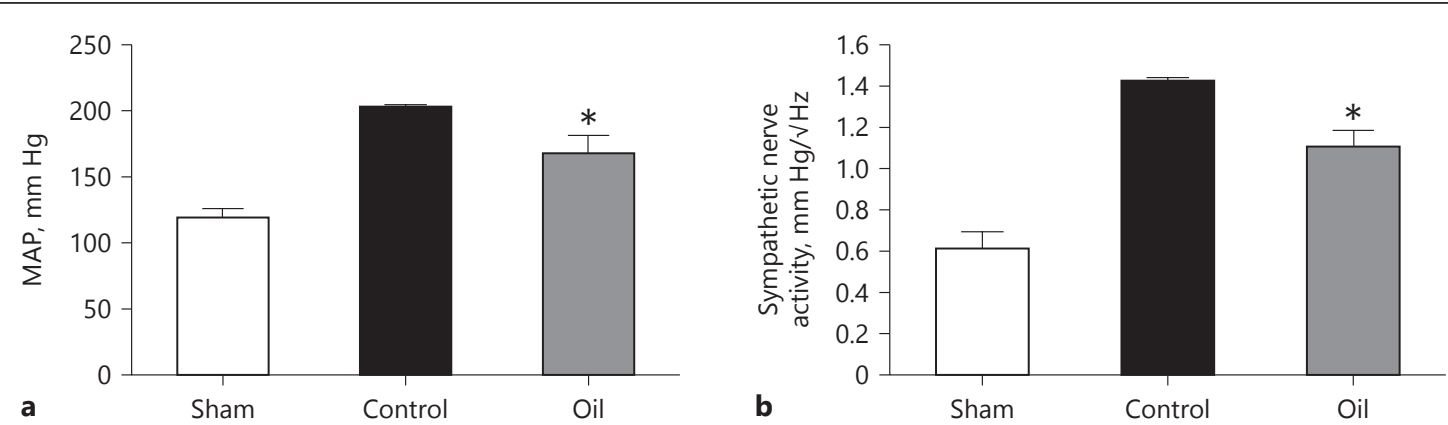
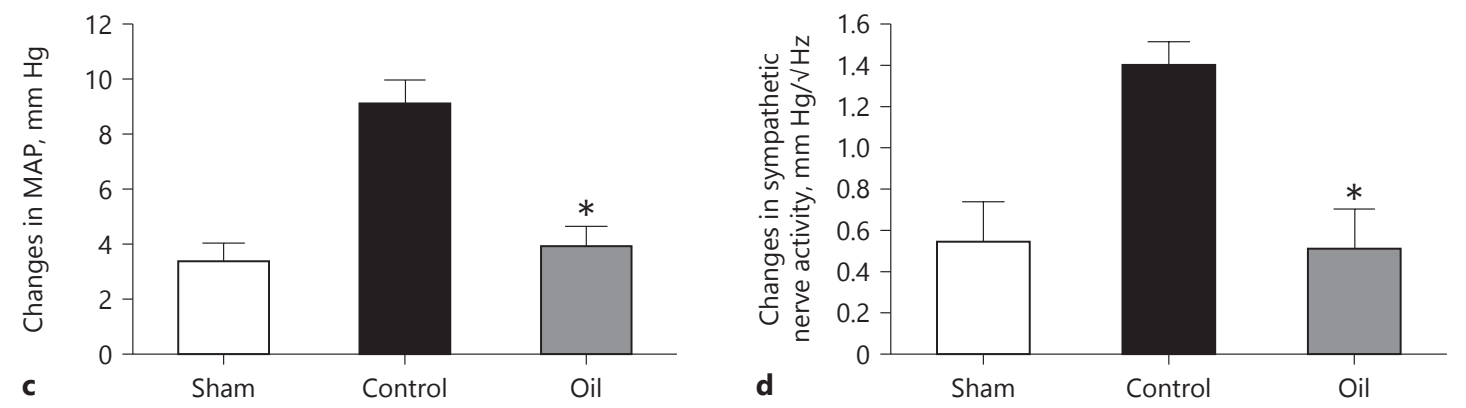

Fig. 4. Effects of flaxseed oil on MAP and sympathetic nerve activity in DOCA-salt rats on day 21 . Flaxseed oil $(1.2 \mathrm{~mL} /$ day $)$ was administered once daily from day 0 to day 21 by gavage. On day 21, MAP and SBP were recorded under freely moving, awake conditions. Then, rats were placed on a reciprocal shaker, and MAP and SBP were recorded under shaker stress conditions. A power spectral density of the low-frequency band $(0.25-0.75 \mathrm{~Hz})$ of SBP fluctuation was calculated as an index of sympathetic nerve activity. The changes in MAP and sympathetic nerve activity were cal- culated by subtracting the value obtained under shaker stress from the value obtained under free-moving, awake conditions. a MAP under freely moving, awake conditions; (b) sympathetic nerve activity under freely moving, awake conditions; (c) MAP under shaker stress conditions; (d) sympathetic nerve activity under shaker stress conditions. Columns and bars show the mean \pm SEM of data from 4 or 6 animals. ${ }^{*} p<0.05$ versus the control group. MAP, mean arterial pressure. 


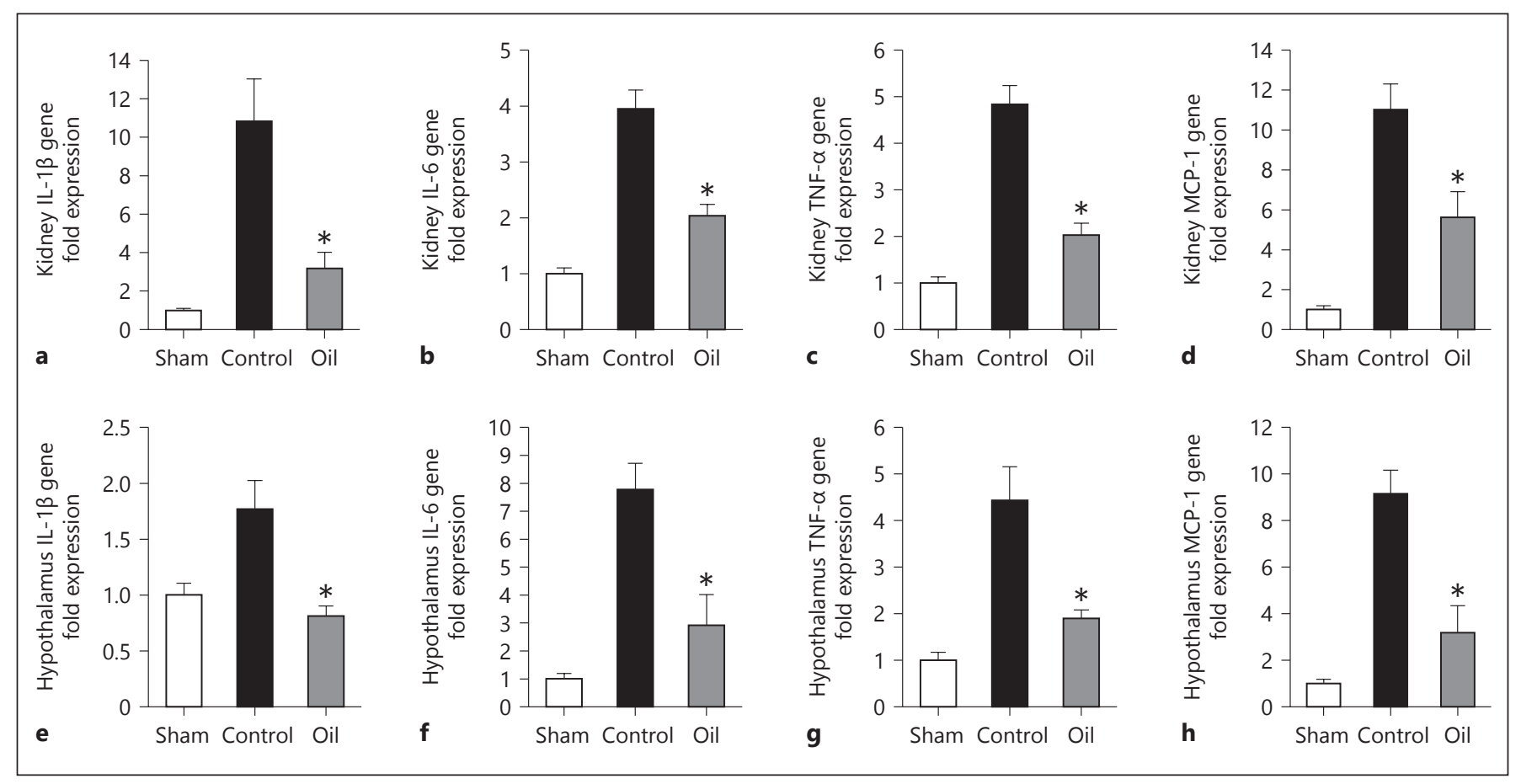

Fig. 5. Effects of flaxseed oil on the increased gene expression of IL-1 $\beta$, IL-6, TNF- $\alpha$, and MCP-1 in the kidney and the hypothalamus of DOCA-salt rats on day 21. Flaxseed oil $(1.2 \mathrm{~mL} /$ day $)$ was administered once daily from day 0 to day 21 by gavage. Rats were sacrificed on day 21 , the kidney and the hypothalamus was removed, and the gene expression of IL- $1 \beta(\mathbf{a}, \mathbf{e})$, IL-6 (b, f), TNF- $\alpha$ (c, g), and MCP-1 (d, h) was measured using quantitative real-time PCR. Columns and bars show the mean \pm SEM of data from 4 or 6 animals. ${ }^{*} p<0.05$ versus the control group. IL- $1 \beta$, interleukin- 1 beta; IL-6, interleukin-6; TNF- $\alpha$, tumor necrosis factor-alpha. MCP-1, monocyte chemoattractant protein-1.

Excessive activation of sympathetic nerve activity is a well-known cause of human hypertension. Increased sympathetic nerve activity is also involved in DOCA-salt hypertension during the early phase (1-5 days after starting treatment) and developed phase (2-6 weeks after starting treatment) [28-30]. In the present study, we demonstrated that flaxseed oil significantly suppressed the increase in sympathetic nerve activity in DOCA-salt rats. Thus, the suppression of the overactive sympathetic nervous system is thought to be one of the mechanisms of the antihypertensive effects of flaxseed. This action may play a role in the suppressive effects on the development of hypertension in the early phase of DOCA-salt treatment in addition to the effects in the developed phase. Eicosapentaenoic acid and docosahexaenoic acid, metabolites of ALA, were reported to lead to serotonin release and improve the accessibility of serotonin to its receptors [28, 31]. Released serotonin activates the $5-\mathrm{HT} 1 \mathrm{~B} / 1 \mathrm{D}$ receptor expressed on sympathetic nerve terminals, decreasing noradrenalin release, thereby suppressing sympathetic neurotransmission $[32,33]$. There-
60

Pharmacology 2020;105:54-62 DOI: $10.1159 / 000502789$
Watanabe/Ohata/Fukanoki/Fujimoto/ Matsumoto/Nessa/Toba/Kobara/Nakata 
fore, the modulation of serotonergic neurotransmission is likely involved in the action of flaxseed on the sympathetic nervous system. In addition, under stress conditions, increased sympathetic nerve activity and MAP were suppressed by flaxseed oil, implying that flaxseed is involved in stress tolerance. Reduction of stress is considered useful for preventing increased blood pressure because stress raises the blood pressure via sympathetic overactivity. Docosahexaenoic acid and eicosapentaenoic acid derived from ALA activate serotonergic neurotransmission and may have stress-reducing and relaxing effects.

Several studies reported that hypertension is associated with many circulating inflammatory factors [34, 35]. Increased inflammatory factors are also related to the increased risk of hypertension in normotensive individuals [36]. In recent years, inflammation in the brain has received increased attention as a cause of sympathoexcitation [37]. Hence, an inflammatory-sympathetic mechanism is a key element in the pathogenesis of hypertension. We found increased gene expression of inflammatory mediators (IL- $1 \beta$, IL- 6 , TNF- $\alpha$, and MCP-1) in the hypothalamic region of DOCA-salt rats, as in previous reports $[14,15]$. The increase in the production of proinflammatory cytokines and the infiltration of activated microglia were observed in the hypothalamus of the animal models of hypertension $[37,38]$. The proinflammatory cytokines were reported to induce neuronal excitation directory [39]. Therefore, microglial activation and the subsequent production of proinflammatory cytokines may affect neuronal excitability in the hypothalamus and induce sympathoexcitation. In this study, flaxseed oil markedly suppressed the increase in proinflammatory cytokines and chemokines observed in DOCA-salt rats. Several reports have revealed that ALA and its metabolites reduce microglial activation and the subsequent production of proinflammatory cytokines in animal models of neuroinflammation $[40,41]$. Taken together, the anti-inflammatory effects of ALA and its metabolites in the brain and the subsequent suppression of sympathetic activity may play roles in the antihypertensive effects of flaxseed in DOCA-salt rats.

\section{Conclusion}

Flaxseed exhibited antihypertensive and renoprotective effects in DOCA-salt rats. Environmental stress-induced pressure was also attenuated by flaxseed. These effects were likely due to ALA. Furthermore, suppression of renal ACE activation, sympathetic nervous activation, and kidney and brain inflammation were suggested to be partially involved in the antihypertensive and renoprotective effects of flaxseed. Therefore, dietary intake of flaxseed may be a useful therapeutic strategy for the management of hypertension.

\section{Acknowledgment}

This study was partially funded by Nippon Flour Mills Co., Ltd.

\section{Disclosure Statement}

Dr. Tetsuo Nakata received scholarship from Nippon Flour Mills Co., Ltd. The remaining authors declare no conflicts of interest.

\section{References}

1 Ferrara LA, Ricci F, Viola S, DE Luca G, Ferrara F, DI Fronzo V, et al. Dietary pattern and blood pressure control in a hypertension outpatient clinic. Hypertens Res. 2007 Nov; 30(11):1043-50.

2 Kawamura A, Kajiya K, Kishi H, Inagaki J, Mitarai M, Oda H, et al. Effects of the DASHJUMP dietary intervention in Japanese participants with high-normal blood pressure and stage 1 hypertension: an open-label single-arm trial. Hypertens Res. 2016 Nov; 39(11):777-85

3 Rodriguez-Leyva D, Weighell W, Edel AL, LaVallee R, Dibrov E, Pinneker R, et al. Potent antihypertensive action of dietary flaxseed in hypertensive patients. Hypertension. 2013 Dec;62(6):1081-9.
4 Al-Bishri WM. Favorable effects of flaxseed supplemented diet on liver and kidney functions in hypertensive Wistar rats. J Oleo Sci. 2013;62(9):709-15.

5 Velasquez MT, Bhathena SJ, Ranich T, Schwartz AM, Kardon DE, Ali AA, et al. Dietary flaxseed meal reduces proteinuria and ameliorates nephropathy in an animal model of type II diabetes mellitus. Kidney Int. 2003 Dec;64(6):2100-7.

6 Prasad K. Flaxseed and cardiovascular health. J Cardiovasc Pharmacol. 2009 Nov;54(5): 369-77.

7 Ogawa A, Suzuki Y, Aoyama T, Takeuchi H. Dietary alpha-linolenic acid inhibits angiotensin-converting enzyme activity and mRNA expression levels in the aorta of spon- taneously hypertensive rats. J Oleo Sci. 2009; 58(7):355-60.

8 Prasad K. Secoisolariciresinol Diglucoside (SDG) Isolated from Flaxseed, an Alternative to ACE Inhibitors in the Treatment of Hypertension. Int J Angiol. $2013 \mathrm{Dec} ; 22(4)$ : 235-8.

9 Sánchez D, Quiñones M, Moulay L, Muguerza B, Miguel M, Aleixandre A. Changes in arterial blood pressure of a soluble cocoa fiber product in spontaneously hypertensive rats. J Agric Food Chem. 2010 Feb;58(3):1493-501.

10 Seifi B, Kadkhodaee M, Zahmatkesh M, Golab F, Bakhshi E. Changes in serum and renal vitamin E levels in deoxycorticosterone acetate-salt hypertensive rats. Transplant Proc. 2009 Sep;41(7):2910-1. 
11 Toba H, Yoshida M, Tojo C, Nakano A, Oshima Y, Kojima Y, et al. L/N-type calcium channel blocker cilnidipine ameliorates proteinuria and inhibits the renal renin-angiotensin-aldosterone system in deoxycorticosterone acetate-salt hypertensive rats. Hypertens Res. 2011 Apr;34(4):521-9.

12 Wang D, Luo Y, Myakala K, Orlicky DJ, Dobrinskikh E, Wang X, et al. Serelaxin improves cardiac and renal function in DOCAsalt hypertensive rats. Sci Rep. 2017 Aug;7(1): 9793.

13 Basting T, Lazartigues E. DOCA-Salt Hypertension: an Update. Curr Hypertens Rep. 2017 Apr;19(4):32.

14 Xia H, Sriramula S, Chhabra KH, Lazartigues E. Brain angiotensin-converting enzyme type 2 shedding contributes to the development of neurogenic hypertension. Circ Res. 2013 Oct; 113(9):1087-96.

15 Sriramula S, Xia H, Xu P, Lazartigues E. Brain-targeted angiotensin-converting enzyme 2 overexpression attenuates neurogenic hypertension by inhibiting cyclooxygenasemediated inflammation. Hypertension. 2015 Mar;65(3):577-86.

16 Guyenet PG. The sympathetic control of blood pressure. Nat Rev Neurosci. 2006 May; 7(5):335-46.

17 Waki H, Gouraud SS. Brain inflammation in neurogenic hypertension. World J Hypertens. 2014;4(1):1-6.

18 Fujita H, Takeda K, Miki S, Morimoto S, Kawa T, Uchida A, et al. Chronic angiotensin blockade with candesartan cilexetil in DOCA/ salt hypertensive rats reduces cardiac hypertrophy and coronary resistance without affecting blood pressure. Hypertens Res. 1997 Dec;20(4):263-7.

19 Oliveira-Sales EB, Toward MA, Campos RR, Paton JF. Revealing the role of the autonomic nervous system in the development and maintenance of Goldblatt hypertension in rats. Auton Neurosci. 2014 Jul; 183:23-9.

20 Toba H, Wang J, Ohigashi M, Kobara M, Nakata T. Telmisartan protects against vascular dysfunction with peroxisome proliferator-activated receptor- $\gamma$ activation in hypertensive 5/6 nephrectomized rats. Pharmacology. 2013;92(5-6):265-75.

21 Ohigashi M, Imai N, Toba H, Kobara M, Nakata T. Pitavastatin Exhibits Protective Effects on Podocytes Accompanied by BMP-7 Up-
Regulation and Rho Suppression. Pharmacology. 2016;97(5-6):265-76.

22 Wang J, Toba H, Morita Y, Nakashima K, Noda K, Tian W, et al. Endothelial dysfunction, macrophage infiltration and $\mathrm{NADPH}$ oxidase-dependent superoxide production were attenuated by erythropoietin in streptozotocin-induced diabetic rat aorta. Pharmacology. 2013;91(1-2):48-58.

23 Xu Z, Li W, Han J, Zou C, Huang W, Yu W, et al. Angiotensin II induces kidney inflammatory injury and fibrosis through binding to myeloid differentiation protein-2 (MD2). Sci Rep. 2017 Mar;7(1):44911.

24 Benigni A, Cassis P, Remuzzi G. Angiotensin II revisited: new roles in inflammation, immunology and aging. EMBO Mol Med. 2010 Jul;2(7):247-57.

25 Peng H, Carretero OA, Alfie ME, Masura JA, Rhaleb NE. Effects of angiotensin-converting enzyme inhibitor and angiotensin type 1 receptor antagonist in deoxycorticosterone acetate-salt hypertensive mice lacking Ren-2 gene. Hypertension. 2001 Mar;37(3):974-80.

26 Kumar KV, Das UN. Effect of cis-unsaturated fatty acids, prostaglandins, and free radicals on angiotensin-converting enzyme activity in vitro. Proc Soc Exp Biol Med. 1997 Apr;214(4): 374-9.

27 Ulu A, Harris TR, Morisseau C, Miyabe C, Inoue $\mathrm{H}$, Schuster G, et al. Anti-inflammatory effects of $\omega-3$ polyunsaturated fatty acids and soluble epoxide hydrolase inhibitors in angiotensin-II-dependent hypertension. J Cardiovasc Pharmacol. 2013 Sep;62(3):285-97.

28 Reid JL, Zivin JA, Kopin IJ. Central and peripheral adrenergic mechanisms in the development of deoxycorticosterone-saline hypertension in rats. Circ Res. 1975 Nov;37(5):56979.

$29 \mathrm{Mu} \mathrm{S}$, Shimosawa T, Ogura S, Wang H, Uetake Y, Kawakami-Mori F, et al. Epigenetic modulation of the renal $\beta$-adrenergic-WNK4 pathway in salt-sensitive hypertension. Nat Med. 2011 May;17(5):573-80.

30 Yemane H, Busauskas M, Burris SK, Knuepfer MM. Neurohumoral mechanisms in deoxycorticosterone acetate (DOCA)-salt hypertension in rats. Exp Physiol. 2010 Jan; 95(1):51-5.

31 Patrick RP, Ames BN. Vitamin D and the omega-3 fatty acids control serotonin synthesis and action, part 2: relevance for $\mathrm{ADHD}$, bipolar disorder, schizophrenia, and impul- sive behavior. FASEB J. 2015 Jun;29(6):220722.

32 Molderings GJ, Werner K, Likungu J, Göthert $M$. Inhibition of noradrenaline release from the sympathetic nerves of the human saphenous vein via presynaptic 5-HT receptors similar to the 5-HT 1D subtype. Naunyn Schmiedebergs Arch Pharmacol. 1990 Oct; 342(4):371-7.

33 Molderings GJ, Fink K, Schlicker E, Göthert M. Inhibition of noradrenaline release via presynaptic 5-HT1B receptors of the rat vena cava. Naunyn Schmiedebergs Arch Pharmacol. 1987 Sep;336(3):245-50.

34 Kim KI, Lee JH, Chang HJ, Cho YS, Youn TJ, Chung WY, et al. Association between blood pressure variability and inflammatory marker in hypertensive patients. Circ J. 2008 Feb; 72(2):293-8.

35 Pruijm M, Vollenweider P, Mooser V, Paccaud F, Preisig M, Waeber G, et al. Inflammatory markers and blood pressure: sex differences and the effect of fat mass in the CoLaus Study. J Hum Hypertens. 2013 Mar;27(3): 169-75.

36 Sesso HD, Buring JE, Rifai N, Blake GJ, Gaziano JM, Ridker PM. C-reactive protein and the risk of developing hypertension. JAMA. 2003 Dec;290(22):2945-51.

37 Santisteban MM, Ahmari N, Carvajal JM, Zingler MB, Qi Y, Kim S, et al. Involvement of bone marrow cells and neuroinflammation in hypertension. Circ Res. 2015 Jul;117(2): 178-91.

38 Shi P, Diez-Freire C, Jun JY, Qi Y, Katovich $\mathrm{MJ}$, Li Q, et al. Brain microglial cytokines in neurogenic hypertension. Hypertension. 2010 Aug;56(2):297-303.

39 Clarkson BD, Kahoud RJ, McCarthy CB, Howe CL. Inflammatory cytokine-induced changes in neural network activity measured by waveform analysis of high-content calcium imaging in murine cortical neurons. Sci Rep. 2017 Aug;7(1):9037.

40 Yip PK, Pizzasegola C, Gladman S, Biggio ML, Marino M, Jayasinghe $M$, et al. The omega-3 fatty acid eicosapentaenoic acid accelerates disease progression in a model of amyotrophic lateral sclerosis. PLoS One. 2013 Apr; 8(4):e61626.

41 Belayev L, Khoutorova L, Atkins KD, Eady TN, Hong S, Lu Y, et al. Docosahexaenoic Acid therapy of experimental ischemic stroke. Transl Stroke Res. 2011 Mar;2(1):33-41. 